\title{
Morphological changes in the Heart in unrelated deaths
}

\author{
Ilias LM ${ }^{1}$, Anupama $\mathrm{P}^{1}$, Gautam $\mathrm{K}^{2}$, Shukla $\mathrm{S}^{3}$, Pai MR ${ }^{4}$, Babitha $\mathrm{AM}^{1}$, \\ Vijayan $\mathrm{P}^{1}$, Sideeque N A ${ }^{1}$, Saleem $\mathrm{S}^{1}$, Umasankar $\mathrm{P}^{5}$ \\ ${ }^{\prime}$ Department of Pathology, M.E.S Medical College, Perinthalmanna, Kerala, India \\ ${ }^{2}$ Department of Pathology, Samyak Diagnostic Pvt. Ltd, Lalitpur, Nepal \\ ${ }^{3}$ Department of Pathology, Ram Manohar Lohia Institute of Medical Sciences, Lucknow, India \\ ${ }^{4}$ Department of Pathology, A.J. Institute of Medical Sciences, Manglore, Karnataka, India \\ ${ }^{5}$ Department of Pathology, M.E.S Medical College, Perinthalmanna, Kerala, India
}

\section{Keywords: \\ Atherosclerosis; \\ Coronary; \\ Atheroma; \\ Fibromuscular; \\ Dysplasia}

\begin{abstract}
Background: Cardiovascular diseases are the major cause of morbidity and mortality worldwide. In the Indian subcontinent, they account for more than $25 \%$ of deaths. Numerous studies have been conducted on the cardiovascular system in cases of sudden death; but there has been a major neglect to study the heart in cases of people who died of unrelated causes.In the present study, we have attempted to study the CVS in detail in those individuals who died of unrelated causes and have tried to asses the prevelance of atherosclerosis, conduction system lesions, inflammatory and valvular pathologies in them.
\end{abstract}

Materials and Methods: The present study was a prospective one conducted from June 2007 to June 2009 in the department of Pathology, Kasturba Medical College, Mangalore. The hearts of persons who died of unrelated causes were studied.

Results: Various lesions encountered in the heart were coronary artery disease $(70.58 \%)$, medial hyperplasia of SAnode (38.23\%) and AV node (55.88\%), chronic inflammation of the conduction system $(55.88 \%)$ and calcification (11.76\%). Malarial myocarditis was seen in 5.88\% and pulmonary stenosis was seen in $2.94 \%$ of the cases. No cardiac pathology was detected in $5.88 \%$ cases.

Conclusion: Our study highlights the prevelace of atherosclerotic changes and conduction system abnormalities in the general population. Hence, we conclude that examination of the CVS is extremely important in cases of sudden death; but it should also be made mandatory in unrelated deaths too, as it can diagnose a lot of hidden pathology.

\section{INTRODUCTION}

Cardiovascular diseases (CVD) are the major cause of morbidity and mortality worldwide. In the Indian

\section{Correspondence:}

Dr. Ilias $L M, M B B S, M D$

Department of Pathology,

M.E.S Medical College, Perinthalmanna, Kerala, India

Email: ilias.laila@gmail.com subcontinent, they account for more than $25 \%$ of deaths. These diseases have been increasing rapidly and it is predicted that within the next 15 years, India will host more than half the cases of heart disease in the world. ${ }^{1,2}$ Coronary artery disease (CAD) has increased in both urban and rural areas with studies indicating that tobacco use, obesity, hypertension, hypercholesterolaemias, diabetes mellitus, low consumption of fruits and vegetables, sedentary 


\begin{tabular}{lc}
$\begin{array}{l}\text { Table 1: Gross grading of luminal narrowing of coronary } \\
\text { arteries }\end{array}$ & Grade \\
\hline Occlusion & 0 \\
\hline Nil & Grade I \\
\hline $\mathbf{2 5 \%}$ & Grade II \\
$\mathbf{2 6 - 5 0 \%}$ & Grade III \\
\hline $\mathbf{5 1 - 7 5 \%}$ & Grade IV \\
\hline $\mathbf{7 6 - 1 0 0 \%}$ & \\
\hline
\end{tabular}

lifestyles and psychosocial stress being all important determinants of CAD in India. ${ }^{1,3}$ The pattern of CAD in India is perplexing as it appears a decade earlier compared with the age incidence in developed countries. ${ }^{2,4}$

It is a well known fact the common cause of sudden deaths in more than $80 \%$ of cases is severe atherosclerotic coronary artery disease (CAD). In the remaining $20 \%$ of sudden death cases, no coronary lesions are usually found; this was frequently seen in younger individuals; and in them myocardial hypertrophy, valvular pathology, inflammatory diseases and conduction system abnormalities are usually found to be the cause of death. ${ }^{3,5}$

Numerous studies have been conducted on the cardiovascular system in cases of sudden death; but there has been a major neglect to study the heart in cases of people who died due to unrelated causes.

In the present study, we have studied the cardiovascular sytem in detail in those individuals who died of unrelated causes and we have tried to asses the prevelance of atherosclerosis, conduction system lesions, inflammatory and valvular pathologies in them.

The aim of this study was to study the morphological and histopathological changes and lesions in the heart, the valves, the coronaries and conduction system in cases of unrelated deaths.

\section{MATERIAL AND METHODS}

The present study was a prospective one conducted from June 2007 to June 2009 in the department of Pathology, Kasturba Medical College, Mangalore. The hearts of persons who died of unrelated causes like victims of road traffic accidents [RTA], poisoning and unclaimed bodies were studied. The cases were collected from Government Wenlock Hospital, Mangalore. Permission was obtained from institutaional review committee.

The heart with the proximal part of ascending aorta was removed from the body and fixed in $10 \%$ formalin to be evaluated at a later date. The hearts were examined externally to note the size, weight, fat deposition, course of the coronary arteries, contusions, haemorrhages and
Table 2: Age group of study population

\begin{tabular}{ccc}
\hline & \multicolumn{2}{c}{ Unrelated deaths } \\
\cline { 2 - 3 } Age group & & $\%$ \\
\hline $\mathbf{2 5}$ & 7 & 20.59 \\
$\mathbf{2 5 - 3 4}$ & 4 & 11.76 \\
\hline $\mathbf{3 5 - 4 4}$ & 7 & 20.59 \\
$\mathbf{4 5 - 5 4}$ & 14 & 40.18 \\
$\mathbf{5 5 - 6 4}$ & 0 & 0 \\
$\mathbf{2 6 5}$ & 2 & 5.88 \\
Total & 34 & 100 \\
\hline
\end{tabular}

lacerations. The coronary arteries were first studied in situ to note for any thickening or hardening. At $5 \mathrm{~mm}$ intervals, transverse cuts were made along the course of the coronaries and the extent of atherosclerotic changes were noted. The hearts were dissected along the direction of blood flow (Virchow's method). Care was taken not to damage the junction of the superior vena cava (SVC) with the right atrial appendage as this site harboured the SA node.

Once the heart was opened, the circumferences of the four valves were noted; presence of any thrombus or fibrosis was also noted.The myocardial thickness was taken $1 \mathrm{~cm}$ above and below the atrioventricular valves. The heart was cleaned of all the post mortem clots and the wet weight was recorded.

The SA node was studied by making an incision extending from the SVC into the right atrial appendage. Another parallel incision was made lateral to the first one and a rectangular block of tissue was obtained. The nodal artery was looked for grossly and once identified, thin parallel sections were given.

The AV node was examined by making a linear incision just lateral to the coronary sinus ostia, extending up to the medial papillary muscle of the right ventricle. A parallel incision was made $1 \mathrm{~cm}$ lateral to the first one and the block of tissue was removed. This block was divided into two; the lower part containing the muscular part of the IVS along with the bundles and the upper part containing the AV node and bundle of His. Thin longitudinal sections were given from the upper part and transverse sections were given from the lower part to study the respective areas. ${ }^{2}$ The coronary arteries were scrutinized for any atheroma, and if present the gross grading of the narrowing was done (Table 1).

Presence of complicated lesions like haemorrhage, thrombus and rupture of plaque were also looked for. The coronary arteries which were heavily calcified were taken and kept for decalcification in formic acid $(\mathrm{HCOOH}=46.03)$. Routine sections were taken from SA and AV nodes, Left main coronary artery (LMCA), Left circumflex artery (LCXA), Left anterior descending artery (LADA), Right coronary artery (RCA), Rt.ventricle and Lt. ventricle.Additional 
Table 3: Various pathological lesions found in the heart

\begin{tabular}{lcc}
\hline \multicolumn{1}{c}{ Pathological lesions } & No. of cases & \% \\
\hline $\begin{array}{l}\text { Atherosclerotic coronary artery disease with } \\
\text { and without conduction system lesions }\end{array}$ & 22 & 64.7 \\
Valvular heart disease-Pulmonary stenosis & 1 & 2.94 \\
Malaria & 2 & 5.88 \\
Conduction system lesions only & 8 & 23.53 \\
No significant cardiac pathology & 1 & 2.94 \\
Total & $\mathbf{3 4}$ & $\mathbf{1 0 0}$
\end{tabular}

sections were given in case any gross pathological lesions were found.

The sections were then processed by routine paraffin embedding techniques. Three to five micron-thick sections were prepared and stained with Haematoxylin and Eosin. Masson Trichrome stain was also employed to study the morphologic changes in the coronary arteries like atheroma and fibrous thickenings. It also helped to look for fibrosis within the nodes.

\section{RESULTS}

This was a prospective study conducted in the Department of Pathology, Kasturba Medical College, Mangalore from June 2007 to June 2009. Thirty four cases of people who died of unrelated causes were studied; 29 cases (85.3\%) were males whereas $5(14.70 \%)$ were females. The youngest subject was a 16 year old girl and the oldest was an 82 year old man (Table 2). The causes of death in them were, poisoning (23.53\%), 20.59\% cases were found dead, $11.76 \%$ cases of electrocution, $5.9 \%$ died due to hanging; drowning and burns constituted $2.94 \%$ of the cases each.

The various histopatholological lesions encountered in them were atherosclerosis, malaria, pulmonary stenosis and conduction system lesions. (Table 3).

Normal right ventricular wall thickness is $0.3-0.5 \mathrm{~cm}$. Right ventricular wall hypertrophy with reduced chamber size and reduced pulmonary valve circumference $(0.5 \mathrm{~cm})$ was seen
Table 4: Microscopic changes in SA node

\begin{tabular}{lcc}
\hline \multicolumn{1}{c}{$\begin{array}{c}\text { Microscopic } \\
\text { features in SA } \\
\text { node }\end{array}$} & \multicolumn{2}{c}{ Unrelated deaths } \\
\cline { 2 - 3 } & No. of cases & $\%$ \\
\hline $\begin{array}{l}\text { Fibromuscular } \\
\text { dysplasia (FMD) }\end{array}$ & 6 & 17.65 \\
\hline Fat infiltration & 4 & 11.76 \\
\hline $\begin{array}{l}\text { FMD+ fat } \\
\text { infiltration }\end{array}$ & 9 & 26.47 \\
\hline Unremarkable & 9 & 26.47 \\
\hline Not sampled & 6 & 17.65 \\
\hline Total & 34 & 100 \\
\hline
\end{tabular}

in one case of congenital pulmonary valve stenosis.Normal pulmonary valve circumference is $7-9 \mathrm{~cm}$. The normal left ventricular wall thickness is $1-1.5 \mathrm{~cm}$. Left ventricular hypertrophy was seen in 4 out of 34 cases (11.76\%).

Degenerative changes were noted in the SA node in 19 out of 34 cases $(55.88 \%)$ (Table4 and 5). Degenerative and pathological changes in the AV node was seen in 29 out of 34 cases $(85.29 \%)$ (Table 6 and 7 )

\section{Coronary atherosclerosis}

Atheromas in the coronaries were seen in in 24 out of 34 cases $(70.59 \%)$ of cases.(Table 8). LMCA---Grade V (7 cases, fig. 1) and grade VI atheroma (1 case, fig.2) were seen in the LMCA in 8 out of 34 cases. (23.52\%). Grade II (1 case), Grade III (4 cases) and Grade IV (6 cases) atheromas were seen in 11 cases out of $34(32.35 \%)$. LADA--Grade $\mathrm{V}$ (7 cases) and Grade VI (1 case )atheromas were seen in 8 out of 34 cases (23.53\%) .Grade III (3 cases)and Grade IV (5 cases)atheromas were seen in 8 out of 34 cses. (23.53\%). LCXA--5 cases of Grade V atheroma (14.70\%), 2 cases of G III and 4 cases of G IV atheromas (17.65\%) were seen in 34 cases of death due to other causes. RCA--3 cases of grade V and 1 case of grade VI atheroma (11.76\%) was noted.Also there were 2 cases each of grade II and III atheroma and 4 cases of grade IV atheroma (23.52\%). Coronary atheromas were seen involving all the 4 arteries

Table 5: Distribution by age groups and microscopic features in SA node

\begin{tabular}{|c|c|c|c|c|c|c|c|c|c|c|c|c|c|c|}
\hline \multirow{3}{*}{$\begin{array}{l}\text { Microscopic features in } \\
\text { SA node }\end{array}$} & \multicolumn{14}{|c|}{ Age group } \\
\hline & \multicolumn{2}{|c|}{$<25$} & \multicolumn{2}{|c|}{$25-34$} & \multicolumn{2}{|c|}{$35-44$} & \multicolumn{2}{|c|}{$45-54$} & \multicolumn{2}{|c|}{$55-64$} & \multicolumn{2}{|c|}{$\geq 65$} & \multicolumn{2}{|c|}{ Total } \\
\hline & $\begin{array}{l}\text { no of } \\
\text { cases }\end{array}$ & $\%$ & $\begin{array}{l}\text { no of } \\
\text { cases }\end{array}$ & $\%$ & $\begin{array}{l}\text { no of } \\
\text { cases }\end{array}$ & $\%$ & $\begin{array}{l}\text { no of } \\
\text { cases }\end{array}$ & $\%$ & $\begin{array}{l}\text { no of } \\
\text { cases }\end{array}$ & $\%$ & $\begin{array}{l}\text { no of } \\
\text { cases }\end{array}$ & $\%$ & $\begin{array}{l}\text { no of } \\
\text { cases }\end{array}$ & $\%$ \\
\hline FMD & 1 & 2.94 & 2 & 5.88 & 0 & 0 & 2 & 5.88 & 0 & 0 & 1 & 2.94 & 6 & 17.64 \\
\hline Fat infiltration(fat) & 0 & 0 & 0 & 0 & 2 & 5.88 & 2 & 5.88 & 0 & 0 & 0 & 0 & 4 & 11.76 \\
\hline FMD+ Fat & 0 & 0 & 1 & 2.94 & 1 & 2.94 & 7 & 20.59 & 0 & 0 & 0 & 0 & 9 & 26.47 \\
\hline Unremarkable & 4 & 11.76 & 1 & 2.94 & 2 & 5.88 & 2 & 5.88 & 0 & 0 & 0 & 0 & 9 & 26.47 \\
\hline Not sampled & 2 & 5.88 & 0 & 0 & 2 & 5.88 & 1 & 2.94 & 0 & 0 & 1 & 2.94 & 6 & 17.65 \\
\hline Total & 7 & 20.59 & 3 & 8.82 & 6 & 17.64 & 7 & 20.59 & 0 & 0 & 2 & 5.88 & 34 & 100 \\
\hline
\end{tabular}


Table 6: Distribution of microscopic features of AV node

\begin{tabular}{lcc}
\hline Microscopic features in AV node & \multicolumn{2}{c}{ Frequency (\%) } \\
\hline Fat & 1 & 2.94 \\
\hline FMD+Fat & 5 & 14.7 \\
\hline C.I & 8 & 23.5 \\
\hline FMD+C.I & 3 & 8.82 \\
\hline Fat+C.I & 1 & 2.94 \\
\hline FMD+ Fat+C.I & 3 & 8.82 \\
\hline Fib+C.I & 2 & 5.88 \\
\hline FMD+ Fat+Fib+C.I & 2 & 5.88 \\
\hline FMD+Cal & 1 & 2.94 \\
\hline Fat+Cal & 2 & 5.88 \\
\hline Fib+Cal & 1 & 2.94 \\
\hline Unremarkable & 4 & 11.76 \\
\hline Not sampled & 1 & 2.94 \\
\hline TOTAL & $\mathbf{3 4}$ & $\mathbf{1 0 0}$ \\
\hline
\end{tabular}

[FMD-Fibromuscular Dysplasia, Fat-Fat infiltration, Fib-Fibrosis, C.Ichronic inflammation, Cal-calcification]

and involving 3 arteries in 5 cases each (14.70\% each). (Table 8) Complicated atheromas were in 6 out of 34 cases (17.65\%). The commonest complications noted was critical stenosis followed by thrombus and haemorrhage.(Table 9)

\section{DISCUSSION}

A random study of 34 autopsy cases, died of unrelated causes was done to evaluate the incidence of various types of heart diseases and relative frequency of these diseases in the population. Cases included were poisoning, RTA, hanging, burns etc. This study was an attempt to asses the load of cardiac diseases in an otherwise normal group of people. A detailed study of the conduction system was also undetaken.

There were 5 females and 29 males and the male to female ratio was 5.8:1. The youngest was a 16 year old girl who had hung herself and the oldest was an 82 year old man who had drowned (Table 3). Baroldi et al6 studied the cardiovascular system in those who had accidental deaths. Of the 97 accident cases in his study, 88 cases were males and 9 were females $(\mathrm{M} / \mathrm{F}=9.7: 1)$. In the present study, 34 cases were studied in the age range 16-82 years (29 males to 5 females). The male to female ratio was (5.8:1).

Heart weight was considered pathological when it was $\geq 500$ gm. In the study by Baroldi et al4, the heart weight $(\geq 500$ gm) was noted in 10 cases belonging to the accident group (10.3\%). In the present study, pathological increase in heart weight was noted in 1 case (2.94\%); seen in a 22 year old female who had died of RTA, but on autopsy was diagnosed as a case of congenital pulmonary valve stenosis.

\section{Coronary atherosclerosis}

Coronary atheromas of different grades were seen in all 97 accident cases $(100 \%)$ studied by Baroldi et $\mathrm{al}^{6}$ and in 24 out of 34 cases in the present study (70.58\%).

The incidence of critical stenosis involving the coronaries was lower in the present study (17.64\%) when compared

Table 7: Age groups and microscopic features of the AV node

\begin{tabular}{|c|c|c|c|c|c|c|c|c|c|c|c|c|c|c|}
\hline \multirow{3}{*}{$\begin{array}{l}\text { Microscopic features in } \\
\text { AV node }\end{array}$} & \multicolumn{14}{|c|}{ Age group } \\
\hline & \multicolumn{2}{|c|}{$<25$} & \multicolumn{2}{|c|}{$25-34$} & \multicolumn{2}{|c|}{$35-44$} & \multicolumn{2}{|c|}{$45-54$} & \multicolumn{2}{|c|}{$55-64$} & \multicolumn{2}{|c|}{$\geq 65$} & \multicolumn{2}{|c|}{ Total } \\
\hline & $\begin{array}{l}\text { no of } \\
\text { cases }\end{array}$ & $\%$ & $\begin{array}{l}\text { no of } \\
\text { cases }\end{array}$ & $\%$ & $\begin{array}{l}\text { no of } \\
\text { cases }\end{array}$ & $\%$ & $\begin{array}{l}\text { no of } \\
\text { cases }\end{array}$ & $\%$ & $\begin{array}{l}\text { no of } \\
\text { cases }\end{array}$ & $\%$ & $\begin{array}{l}\text { no of } \\
\text { cases }\end{array}$ & $\%$ & $\begin{array}{l}\text { no of } \\
\text { cases }\end{array}$ & $\%$ \\
\hline Fat & 0 & 0 & 0 & 0 & 0 & 0 & 1 & 2.94 & 0 & 0 & 0 & 0 & 1 & 2.94 \\
\hline FMD+Fat & 0 & 0 & 0 & 0 & 1 & 2.94 & 4 & 11.7 & 0 & 0 & 0 & 0 & 5 & 14.7 \\
\hline C.I & 5 & 14.70 & 1 & 2.94 & 2 & 5.88 & 0 & 0 & 0 & 0 & 0 & 0 & 8 & 23.53 \\
\hline FMD+C.I & 0 & 0 & 1 & 2.94 & 1 & 2.94 & 1 & 2.94 & 0 & 0 & 0 & 0 & 3 & 8.82 \\
\hline Fat+C.I & 0 & 0 & 0 & 0 & 0 & 0 & 1 & 2.94 & 0 & 0 & 0 & 0 & 1 & 2.94 \\
\hline FMD+ Fat+C.I & 0 & 0 & 0 & 0 & 1 & 2.94 & 2 & 5.88 & 0 & 0 & 0 & 0 & 3 & 8.82 \\
\hline Fib+C.I & 0 & 0 & 0 & 0 & 2 & 5.88 & 0 & 0 & 0 & 0 & 0 & 0 & 2 & 5.88 \\
\hline $\begin{array}{l}\text { FMD+ } \\
\text { Fat+Fib+C.I }\end{array}$ & 0 & 0 & 0 & 0 & 0 & 0 & 2 & 5.88 & 0 & 0 & 0 & 0 & 2 & 5.88 \\
\hline Fib+Cal & 0 & 0 & 0 & 0 & 0 & 0 & 1 & 2.94 & 0 & 0 & 0 & 0 & 1 & 2.94 \\
\hline FMD+Cal & 0 & 0 & 0 & 0 & 0 & 0 & 0 & 0 & 0 & 0 & 1 & 2.94 & 1 & 2.94 \\
\hline Fat+Cal & 0 & 0 & 0 & 0 & 0 & 0 & 1 & 2.94 & 0 & 0 & 1 & 2.94 & 2 & 5.88 \\
\hline Unremarkable & 1 & 2.94 & 2 & 5.88 & 0 & 0 & 1 & 2.94 & 0 & 0 & 0 & 0 & 4 & 11.7 \\
\hline Not sampled & 1 & 2.94 & 0 & 0 & 0 & 0 & 0 & 0 & 0 & 0 & 0 & 0 & 1 & 2.94 \\
\hline Total & 7 & 20.59 & 4 & 11.76 & 7 & 20.6 & 12 & 28.75 & 0 & 35.3 & 3 & 8.82 & 34 & 100 \\
\hline
\end{tabular}




\begin{tabular}{|c|c|c|}
\hline \multirow{2}{*}{ Atheroma } & & \\
\hline & No. of cases & $\%$ \\
\hline LMCA & 6 & 17.64 \\
\hline RCA & 1 & 2.94 \\
\hline LADA & 1 & 2.94 \\
\hline LMCA+RCA & 1 & 2.94 \\
\hline LMCA+RCA+LADA & 4 & 11.76 \\
\hline RCA+LADA+LCXA & 1 & 2.94 \\
\hline LADA+LMCA+LCXA & 5 & 14.70 \\
\hline LMCA+RCA+LADA+LCXA & 5 & 14.70 \\
\hline UNREMARKABLE & 10 & 29.4 \\
\hline TOTAL & 24 & 100 \\
\hline
\end{tabular}

to the study of Baroldi et al6 (39.17\%) (Table 10). In both the studies, the incidence of coronary atherosclerosis with critical stenosis involving 2 vessels or $3 \geq 3$ vessels was less. This feature was similar in both the studies.

Because of theses findings Baroldi et $\mathrm{al}^{6}$ argued that severe stenosis even multiple in nature can be ineffective in producing sudden death; as these individuals survived with complicated atheromas. This feature could be explained due to the presence of collateral circulation between the coronaries, thus preventing fatal ischaemia.

Left anterior descending artery was the most common artery to be involved by atherosclerosis according to Baroldi et $\mathrm{al}^{6}$ which was not in concordance with the present study; where the left main coronary artery was more frequently involved. (Table 11)

\section{Conduction system}

The study of the conduction system (CS) was included to look for the evidence of various pathologies affecting the nodes in an otherwise normal population.

Charlton et $\mathrm{al}^{7}$ examined conduction system in accident cases in 15 hearts. In his study, 10 cases showed abnormalities in the conduction system; fibromuscular dysplasia (fig. $3 \mathrm{~A}$ and B) was seen affecting the nodal arteries in the age range of

Table 10: Comparison of atherosclerotic changes between the studies

\begin{tabular}{ccc}
\hline $\begin{array}{c}\text { Atherosclerosis involving } \\
\text { coronary arteries with critical } \\
\text { stenosis }\end{array}$ & $\begin{array}{c}\text { Baroldi et al6 } \\
(\mathbf{9 7})\end{array}$ & $\begin{array}{c}\text { Present study } \\
\mathbf{( 3 4 )}\end{array}$ \\
\hline Single vessel & $26(26.80 \%)$ & $4(11.76 \%)$ \\
Double vessel & $9((9.28 \%)$ & $1(2.94 \%)$ \\
$3 />3$ vessel & $3(3.09 \%)$ & $1(2.94 \%)$ \\
Total & $\mathbf{3 8}(\mathbf{3 9 . 1 7 \% )}$ & $\mathbf{6 ( 1 7 . 6 4 \% )}$ \\
\hline
\end{tabular}

Table 9: Complicated atheroma in individual coronary arteries

\begin{tabular}{|lcc|}
\hline \multirow{2}{*}{ Complicated atheroma } & & \\
\cline { 2 - 3 } & No. of cases & $\%$ \\
\hline LMCA & 2 & 5.88 \\
\hline LADA & 2 & 5.88 \\
\hline RCA+LCXA & 1 & 2.94 \\
\hline LADA+LMCA+LCXA & 1 & 2.94 \\
\hline TOTAL & $\mathbf{6}$ & $\mathbf{1 7 . 6 5}$ \\
\hline
\end{tabular}

7-59 years. In the present study, FMD was seen affecting the nodal arteries in the age range of $24-82$ years.

FMD of the nodal arteries was seen affecting young and old individuals alike; in both the study by Charlton et $\mathrm{al}^{7}$ and in the present study. However, other degenerative changes like fibrosis and fat infiltration were seen more in the elderly in the present study, and was similar to the findings of Charlton et al. ${ }^{7}$ (Table 12) Another study was conducted by Nishida et al8; in which they studied the CS in 42 accidental cases. They found 2 cases with FMD of AV nodal artery. ${ }^{8}$

Pathogenesis of FMD is still unclear. Congenital or acquired defects of smooth muscle/ collagen /elastin or congenital or acquired defects of local arterial innervations may all play contributory roles. Sinus node artery is an unusually stressed artery, coursing through a comparatively dense collagen sheath, which might render it susceptible to mural disease. ${ }^{2,9}$

The present study showed FMD of the SA node artery in $44.11 \%$ of cases (15 cases) and FMD of AV node artery (14 cases) in $41.17 \%$ cases. FMD is histologically similar to arterial dysplastic changes seen in renal arteries and in other muscular arteries. Many individual reports have linked SCD with nonatherosclerotic narrowing of the SA and AV nodal arteries. Narrowing of these arteries has also been described as a frequent finding in subjects dying of other causes too in literature; as seen in our subjects. Hence, the association of sudden death with the narrowing of sinus nodal artery remains anecdotal. ${ }^{10}$

In the present study, fibrofatty change in SA node and $\mathrm{AV}$ node were seen in $38.23 \%$ and $55.88 \%$ cases respectively which was much higher than the findings of Charton et $\mathrm{al}^{7}$ (Table 12). Presence of mononuclear inflammatory cells was seen in $55.88 \%$ cases which was higher than the findings of Charlton et $\mathrm{al}^{7}$ (Table 12). Charlton et $\mathrm{al}^{7}$ could not explain these collections of mononuclear cells and they thought it was associated with remodelling of cardiac skeleton or with fat infiltration in the nodes.

Calcification in the nodes is described by Gulino et al. ${ }^{10}$ They said that heavy calcification of the aortic valve or the mitral valve annulus may compress the conduction tissue 


\begin{tabular}{ccc}
\hline Table 11: Involvement of coronary arteries & \\
\hline Coronary artery involved & Baroldi et al6 & Present study \\
\hline Left coronary & $40.21 \%$ & $51.76 \%$ \\
\hline Left anterior descending & $86.60 \%$ & $47.05 \%$ \\
\hline Right coronary & $73.20 \%$ & $32.35 \%$ \\
\hline Left circumflex & $53.61 \%$ & $35.3 \%$ \\
\hline
\end{tabular}

\begin{tabular}{|c|c|c|}
\hline $\begin{array}{l}\text { Pathology in conduction } \\
\text { system (most common } \\
\text { changes) }\end{array}$ & $\begin{array}{l}\text { Charlton et } \\
\quad \text { al7 }\end{array}$ & Present study \\
\hline (15 cases) & Present study & $51.76 \%$ \\
\hline (34 cases) & $86.60 \%$ & $47.05 \%$ \\
\hline $\begin{array}{l}\text { Medial hyperplasia of nodal } \\
\text { arteries }\end{array}$ & $5(33.33 \%)$ & $\begin{array}{l}15 / 34 \\
(44.11 \%) \\
\text { SAnode }\end{array}$ \\
\hline 14/34(41.17\%)AVnode & $53.61 \%$ & $35.3 \%$ \\
\hline Fibrofatty change & - & $\begin{array}{l}\text { 13/34(38.23\%) } \\
\text { SAnode }\end{array}$ \\
\hline \multicolumn{3}{|l|}{ 19/34(55.88\%)AVnode } \\
\hline Presence of mononuclear cells & $2(13.33 \%)$ & $\begin{array}{l}\text { 19(55.88\%) } \\
\text { AVnode }\end{array}$ \\
\hline $\begin{array}{l}\text { Presence of myxoid ground } \\
\text { substance }\end{array}$ & $4(26.66 \%)$ & - \\
\hline Calcification & - & $\begin{array}{l}4(11.76 \%) \\
\text { AVnode }\end{array}$ \\
\hline AV nodal tumour & $1(3.22 \%)$ & - \\
\hline
\end{tabular}

or extend as calcific deposits into central fibrous body and conduction tissue. Calcification was seen in $11.76 \%$ of cases in the present study (Table12).

\section{Malarial myocarditis}

Two cases of malarial myocarditis were seen in the present study. Both the cases had disseminated malaria which had involved other organs like liver, spleen, lungs and brain and

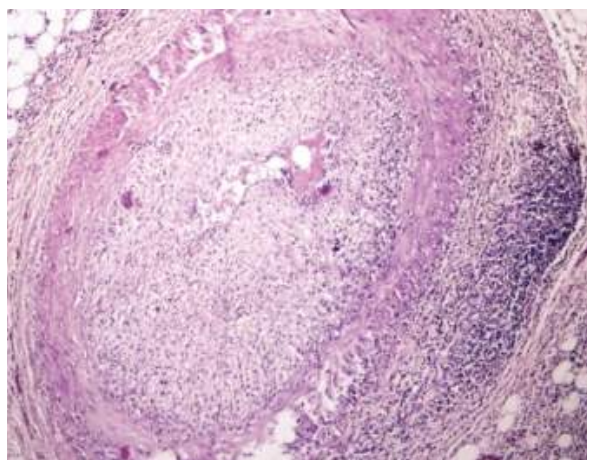

Figure 1: Grade V atheroma obliterating $>90 \%$ of the lumen with dense inflammation (HE stain, X40)

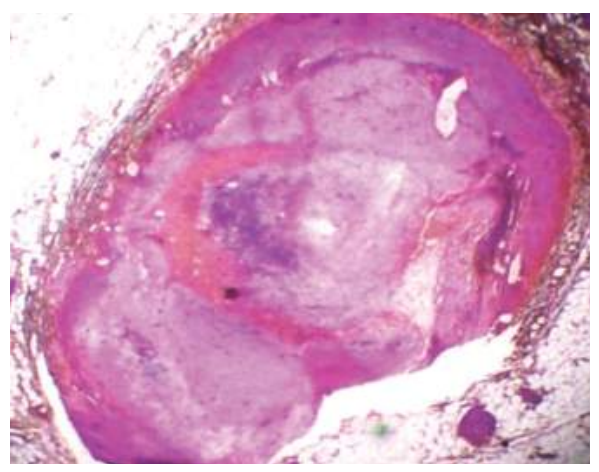

Figure 2: Grade VI atheroma with an attached thrombus and complete obliteration of the lumen (HE stain, X20) was caused by plasmodium falciparum. The myocardium showed numerous capillaries plugged with parasitized red blood cells (RBCs) leading to focal ischaemic changes.

Malaria is still widespread in tropical countries like India and is associated with high morbidity and mortality. ${ }^{3,11}$ This mechanical blockage of capillaries leads to ischaemic cardiomyopathy and induces 'toxic effects' which also plays a significant role in this pathophysiological process;

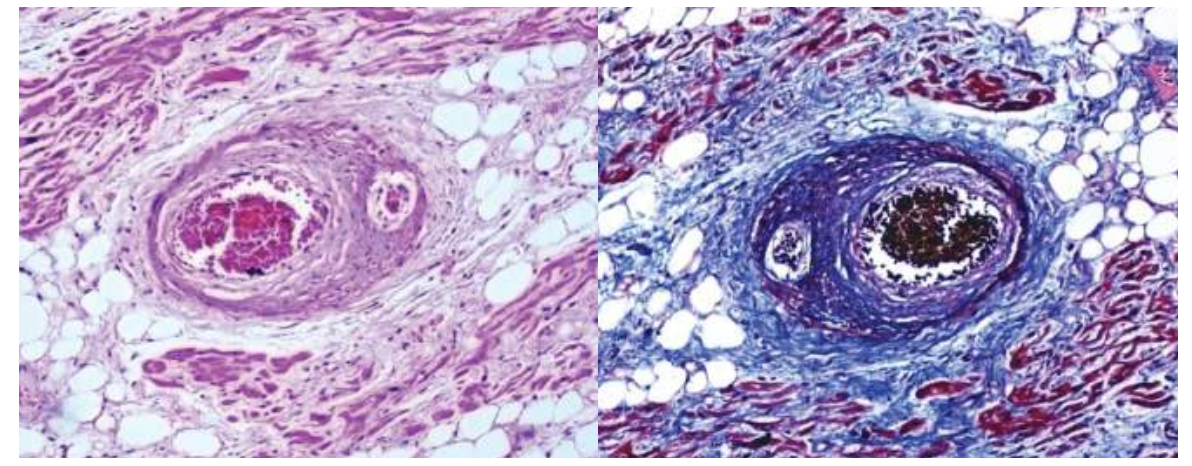

Figure 3: Eccentric fibromuscular dysplasia of AV node artery with fat infiltration (HE stain, X400). B. Masson trichome stain 
mediated by a group of polypeptides with tumour necrosis factor being particularly important. Hence myocardial involvement should be considered as a potential complication in severe plasmodium falciparum infection. ${ }^{3,12}$

\section{Congenital pulmonary stenosis}

One case of isolated congenital pulmonary stenosis with right ventricular hypertrophy $(1.5 \mathrm{~cm})$ and right atrial enlargement was seen in the present study $(2.94 \%)$ in a 22 year old female. It was a case of RTA and pulmonary stenosis was an incidental finding at autopsy. The valves were fused and the circumference was reduced to $0.5 \mathrm{~cm}$.

Pulmonary valve stenosis is one of the more common forms of congenital heart malformations. It was originally described by John Baptist Morgagni in 1762; but pulmonary stenosis as an isolated malformation with no defect in the IVS is very rare.,13 Isolated pulmonic stenosis, if found, is usually valvular as was our case.

\section{CONCLUSION}

- Our study was done in 34 random death cases; it excluded cases of sudden death.This study was undetaken to assess the prevelance of atherosclerosis, conduction sytem abnormalities, valvular pathology and inflammatory conditions in unrelated deaths. Various lesions encountered in the heart were coronary artery disease $(70.58 \%)$, medial hyperplasia of SAnode (38.23\%) and AV node (55.88\%), chronic inflammation of the conduction system (55.88\%) and calcification (11.76\%). Malarial myocarditis was seen in $5.88 \%$ and pulmonary stenosis was seen in $2.94 \%$ of the cases. No cardiac pathology was detected in $2.94 \%$ cases.

- This study once again highlights the importance of cardiac autopsy, even in unrelated causes of deaths.

- In our study we found a case of Pulmonary stenosis in a 22 year old female; a case of RTA; which would have been left undiagnosed if cardiac autopsy had not been undertaken.

- This study also helped to identify malarial myocarditis in 2 cases of unrelated deaths.

- The significance of these changes are not clearly understood, but our study highlights the prevelace of atherosclerotic changes and conduction system abnormalities in the general population.Maybe these changes, later on would have contributed to the morbididty and mortality of these people if they have had survived.

- Hence, we conclude saying that examination of the cardio vascular system is extremely important in cases of sudden death; but it should also be made mandatory in unrelated deaths too, as it can diagnose a lot of hidden pathologies.

\section{REFERENCES}

1. Gupta R, Joshi P, Mohan V, Reddy KS, Yusuf S. Epidemiology and causation of coronary heart disease and stroke in India. Heart 2008;94:16-26.

2. Ilias L. M., Pai M. R., Shukla S. Ponniah A., Gautam K., \& Vijayan, P. (2015). Cardiac conduction system-A detailed study in 46 cases of sudden death. Journal of Pathology of Nepal 2015;5:709-16.

3. Laila M.Ilias, Muktha R.Pai, Saumya Shukla, Keyoor Gautam, Deeshma T, Anupama P.An autopsy study of the heart with an emphasis on the coronaries. Annals Medicus 2015;2:288-300.

4. Park K, Chapter No: 6. Epidemiology of Chronic Non-communicable Diseases and Conditions. In: Park's Textbook Of Preventive and Social Medicine, 20th ed., Park K, Jabalpur, Banarsidas Bhanot Publishers, 2009.p303-5.

5. Suarez-Mier MP, Fernandez-Simon L, Gawallo C. Pathologic Changes of the Cardiac Conduction Tissue in Sudden Cardiac Death. Am J Forensic Med Pathol 1995;16:193-202.

6. Baroldi G, Falzi G, Mariani F. Sudden coronary death. A postmortem study in 208 selected cases compared to 97 "control" subjects. Am Heart J 1979;50:20-31.

7. Charlton I, Williams R. Cardiac Conducting Tissue - A Simplified Technique for Examination of the SA and AV Nodes. Am J Forensic Med Pathol 1990;11:213-8.

8. Nishida, N., Ikeda, N., Kudo, K., Tsuji, A., \& Kiyoshima, A. Forensic significance of conduction system abnormalities as a precise cause of accidental death. International journal of legal medicine 2002;116:344-9.

9. James TN, Marshall TK. Multifocal Stenoses Due to Fibromuscular Dysplasia of the Sinus Node Artery. Circulation 1976; 53:736-42.

10. Gulino SP. Examination of the Cardiac Conduction System - Forensic Application in Cases of Sudden Cardiac Death. Am J Forensic Med Pathol 2003;24:227-38.

11. Chopra P, Chapter No: 8. Myocarditis. In: Illustrated Textbook of Cardiovascular Pathology, 1st ed., Chopra P, New Delhi, Jaypee Brothers Medical Publishers, 2003; p108-18.

12. Mohsen AH, Green ST, West JN, McKendrick MW. Myocarditis associated with Plasmodium falciparum Malaria: A Case Report and a Review of the Literature. J Travel Med 2001;8:219-20.

13. Freedom RM, Benson L, Chapter No: 13A. Congenital Pulmonary Stenosis and Isolated Congenital Pulmonary Insufficiency. In: Natural and modified history of congenital heart disease, 1st ed., Freedom RM, Yoo S, Mikailian H, Williams WG, U.S.A, Blackwell Publishing, 2004.p107-9. 